\title{
CARACTERIZAÇÃO DO RESÍDUO SÓLIDO GERADO NA PLANTA DE BENEFICIAMENTO DE SUCATA UTILIZADA NA PRODUÇÃO DE AÇO *
}

\author{
Ana Flávia Tardin Siviero", \\ Mariana Vilela Galuppo ${ }^{2}$ \\ Matheus Moraes Assumpção Marcellino ${ }^{3}$ \\ Damaris Guimarães ${ }^{4}$ \\ Diego Corrêa Magalhães ${ }^{5}$ \\ Lívia Gomes Pereira ${ }^{6}$
}

Resumo

A "Terra de Sucata" é o coproduto gerado pelo processo de beneficiamento de sucata na indústria siderúrgica. Atualmente, a aplicação desse coproduto é limitada pela falta de uma caracterização completa do mesmo. Dessa forma, o presente trabalho visa à caracterização de tal material para viabilizar o levantamento das possibilidades de aproveitamento do mesmo. A amostragem foi feita em uma usina siderúrgica localizada na cidade de Cariacica, no Espírito Santo. Foram realizadas análises via Difração de Raios-X (DRX) e Microscopia Eletrônica de Varredura acoplada à Espectroscopia de Energia Dispersiva (MEV/EDS). Além disso, foram feitas a determinação de $\mathrm{pH}$, distribuição granulométrica, teor de umidade, densidade e análise elementar. A partir desses experimentos, observou-se que se trata de um material bastante heterogêneo em termos de morfologia, composição e granulometria, o qual apresenta $6,43 \pm 0,15$ de $\mathrm{pH}, 4,53 \% \pm 0,92 \%$ de teor de umidade e $2,25 \mathrm{~g} / \mathrm{cm}^{3} \pm 0,25 \mathrm{~g} / \mathrm{cm}^{3}$ de densidade. Esse material é composto pelos elementos ferro, alumínio, silício, cálcio, zinco, magnésio, manganês, fósforo, enxofre, carbono, titânio, potássio e sódio. A partir da análise de DRX, foi possível identificar a presença das fases quartzo, hematita, calcita, óxido de ferro (II) e outras.

Palavras-chave: “Terra de Sucata”; Resíduo Sólido; Caracterização.

\section{CHARACTERIZATION OF THE SOLID WASTE ORIGINATED FROM THE BENEFICIATION PLANT OF SCRAP METAL USED IN STELL PRODUCTION \\ Abstract}

"Scrap Residue" is a byproduct generated by the process of scrap metal beneficiation in the steel industry. Currently, the application of this byproduct is limited, due to the lack of its complete characterization. Thus, the present work aims to characterize this material to allow the evaluation of its potential utilizations. The sampling was carried out in a steel plant located in Cariacica city, Espírito Santo state, Brazil. X-Ray Diffraction (XRD) and Scanning Electron Microscopy coupled to Dispersive Energy Spectroscopy (SEM/ EDS) analysis were performed. In addition, the following determinations were carried out: $\mathrm{pH}$, granulometric distribution, humidity ratio, density and elemental analysis. From these experiments, it was observed that this material is very heterogeneous, in terms of morphology, composition and granulometry, which presents $6.43 \pm 0.15$ of $\mathrm{pH}, 4.53 \% \pm 0.92 \%$ of moisture content and $2.25 \mathrm{~g} / \mathrm{cm}^{3} \pm$ $0.25 \mathrm{~g} / \mathrm{cm}^{3}$ of apparent density. This material is composed of elements iron, aluminum, silicon, calcium, zinc, magnesium, manganese, phosphorus, sulfur, carbon, titanium, potassium and sodium. From XRD analysis, the following phases were identified: quartz, hematite, calcite, iron (II) oxide and others.

Keywords: Scrap Residue; Solid Waste; Characterization. 
1 Engenharia Química, bacharel, discente, Departamento de Engenharia Rural, Universidade Federal do Espírito Santo, Alegre, Espírito Santo, Brasil.

2 Engenharia Química, bacharel, discente, Departamento de Engenharia Rural, Universidade Federal do Espírito Santo, Alegre, Espírito Santo, Brasil

3 Engenharia Química, bacharel, discente, Departamento de Engenharia Rural, Universidade Federal do Espírito Santo, Alegre, Espírito Santo, Brasil

4 Química Industrial, Doutora em Engenharia de Materiais, Professora Adjunta no Departamento de Engenharia Rural, Universidade Federal do Espírito Santo, Alegre, Espírito Santo, Brasil.

5 Engenheiro Ambiental, Mestre em Public and Environmental Affairs, Pesquisador no Centro de Pesquisas da ArcelorMittal

6 Engenheira Ambiental, Pós-Graduanda em Engenharia de Segurança do Trabalho. Integrante do Núcleo de Coprodutos da ArcelorMittal. 


\section{INTRODUÇÃO}

Atualmente, a sustentabilidade é uma constante na estratégia de negócio do setor industrial. Sabe-se da necessidade de atingir o equilíbrio entre os âmbitos econômico, social e ambiental. Portanto, as organizações estão buscando, de forma rigorosa, atingir esse objetivo. A preocupação em reduzir os danos ao ambiente, mantendo a competitividade, produtividade e lucratividade, conduz a estudos e investimentos em melhorias mais sustentáveis no processo ${ }^{[1]}$.

Esses investimentos vão além do atendimento legal e permeiam pelo desenvolvimento de um novo negócio para as empresas baseado na transformação de resíduos em coprodutos. Isto é, estudar tecnologias para reciclagem e/ou reutilização dos resíduos gerados no processo, ao invés do envio para aterro industrial.

Um dos coprodutos em desenvolvimento no processo de produção de aço é a Terra da Sucata. A sucata ferrosa é uma das principais matérias prima na produção de aço. Hoje, no Brasil, cerca de $30 \%$ do aço produzido é proveniente de reciclagem. No entanto, a sucata recém-chegada à indústria deve passar por um processo de beneficiamento antes de ser carregada ao forno. Esse processo de beneficiamento gera um coproduto denominado "Terra de Sucata" [2; 3]. A Figura 1 apresenta um fluxograma simples do processo de geração da "Terra de Sucata" no local onde foram coletadas as amostras analisadas no presente trabalho, na qual encontra-se destacada a etapa em que tal material é gerado.

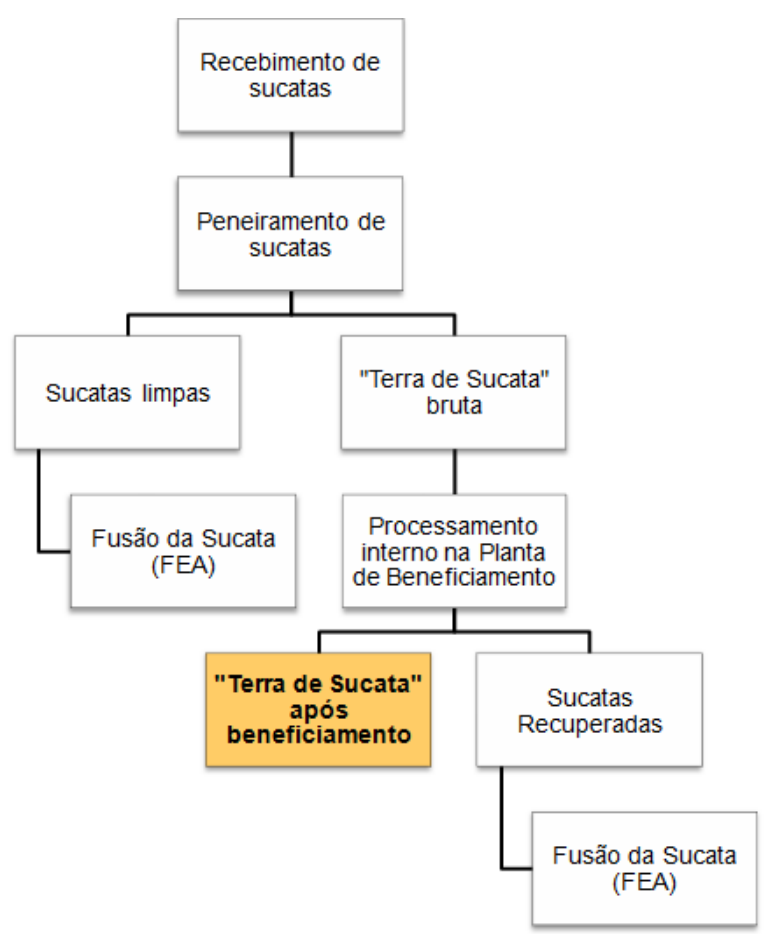

Figura 1. Representação por fluxograma do processo de geração da "Terra de Sucata" da ArcelorMittal Cariacica.

Atualmente, a "Terra de Sucata" tem aplicações limitadas. Diante desse quadro, o levantamento de alternativas de uso para esse material é almejado. No entanto, para 
possibilitar o levantamento de aplicações desse coproduto é necessário um maior conhecimento sobre sua composição e características.

Dentro desse contexto, o presente trabalho foi desenvolvido visando à caracterização desse coproduto proveniente do processo de beneficiamento da sucata que é realizado na ArcelorMittal Cariacica.

\section{MATERIAIS E MÉTODOS}

\subsection{Amostragem}

A amostragem da "Terra de Sucata" foi realizada com base na metodologia descrita na norma da ABNT - NBR 10007:2004 [4], visto que o material se manteve estocado por anos, não havendo, portanto, necessidade de se realizar amostragens periódicas. As amostras foram retiradas do topo, meio e base de diferentes pontos da pilha de "Terra de Sucata", de acordo com a técnica de quarteamento descrita por Luz, Sampaio e França (2010) ${ }^{[5]}$. Esses pontos estão esquematizados na Figura 2.

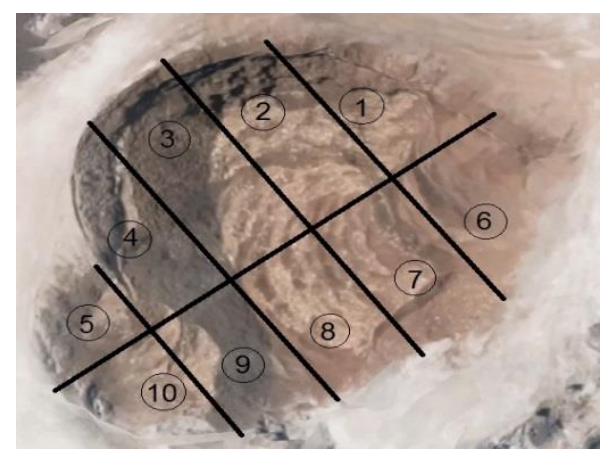

Figura 2. Pontos de amostragem na pilha de "Terra de Sucata" ${ }^{[6]}$ (adaptado pelos autores).

A partir da junção das amostras retiradas dos pontos apresentados na Figura 2, uma nova pilha foi formada. Em seguida, homogeneizou-se e quarteou-se a pilha novamente duas vezes, até que o seu tamanho estivesse de acordo com o volume de amostra desejado [5]. O material coletado foi identificado por uma ficha com informações pertinentes ao aspecto do local de amostragem e foi, em seguida, acondicionado em sacos plásticos.

\subsection{Análise Morfológica e Química}

\subsubsection{Espectroscopia de energia dispersiva (EDS)}

As análises morfológica e elementar (caráter qualitativo) foram realizadas em um equipamento de Microscopia Eletrônica de Varredura acoplado ao Espectrômetro de Energia Dispersiva (MEV/EDS) da marca JEOL, modelo JSM-7100F, localizado no laboratório do Centro de Pesquisas da ArcelorMittal Tubarão.

Retirou-se da amostra uma pequena quantidade do material de granulometria fina, o qual foi depositado em uma fita magnética antes de ser inserido no equipamento para análise. 


\subsubsection{Fluorescência de Raios-X}

A análise química quantitativa foi realizada por Fluorescência de Raios-X (FRX), em um equipamento da marca THERMO ARL, modelo ARL 9900 Intellipower Series, localizado no Laboratório Químico da Aciaria da ArcelorMittal Tubarão.

O preparo da amostra de "Terra de Sucata" para essa análise iniciou-se com sua secagem por aproximadamente 24 horas em uma estufa a 105ㄷ. Em seguida, foram realizadas duas separações granulométricas, passando o material bruto por uma peneira de $3 \mathrm{~mm}$ de abertura e posteriormente por uma de $840 \mu \mathrm{m}$ de abertura.

Foram feitas duas pastilhas, uma com o material que passou pela peneira com abertura de $3 \mathrm{~mm}$ e outra com o material que passou pela peneira com abertura de $840 \mu \mathrm{m}$. Para cada uma delas, 100 gramas da amostra foram pulverizadas (1 pulverização) no moinho de panelas da marca HERZOG. Em seguida, pesou-se 15 gramas do material pulverizado e adicionou-se a ele 2,2 gramas de material aglomerante (amido) para levá-lo novamente ao moinho ( $2^{a}$ pulverização). Posteriormente, o material foi prensado em uma prensa da marca HERZOG, com carga de aproximadamente $25 \mathrm{t}$, para a formação da pastilha.

Durante os ensaios de FRX, ambas as pastilhas foram analisadas. Para isso, foram utilizadas as curvas padrão de materiais que são comumente analisados na ArcelorMittal Tubarão e que apresentam composição parecida com a indicada pelo EDS para a "Terra de Sucata".

\subsubsection{Teor de Carbono}

Os teores de carbono das amostras pulverizadas com $\mathrm{d}<840 \mu \mathrm{m}$ e $\mathrm{d}<3 \mathrm{~mm}$ foram determinados utilizando-se um aparelho analisador de carbono e enxofre, LECO CS444, localizado no Laboratório Químico da Aciaria da ArcelorMittal Tubarão.

\subsection{Potencial Hidrogeniônico}

Para a determinação do $\mathrm{pH}$, pesou-se 50,00 g da "Terra de Sucata" utilizando uma balança semianalítica, modelo PB3002-S, da marca Mettler Toledo. Em um erlenmeyer, foram adicionados $50 \mathrm{~mL}$ de água destilada ao composto sólido. Agitouse a mistura continuamente por 5 minutos em um agitador automático, modelo TE141 TECNAL. Em seguida, a mistura foi filtrada e o pH do filtrado foi medido com pHmetro da marca Mettler Toledo, o qual foi previamente calibrado. Esse procedimento foi realizado em triplicata.

\subsection{Teor de Umidade}

A análise de teor de umidade da "Terra de Sucata" foi realizada com base na norma ABNT NBR 6457:2016 [7], a qual foi adaptada. Pesou-se em triplicata aproximadamente $10 \mathrm{~g}$ de amostra em balança de modelo PB3002-S, da Mettler Toledo, e identificou-se sua massa como M1. A amostra foi destorrada e colocada em placas de Petri, sendo, em seguida, tampada. 
Os recipientes contendo as amostras previamente pesadas foram mantidos em estufa, a uma temperatura de $105^{\circ} \mathrm{C}$, permanecendo por 24 horas. Em seguida, 0 material foi transferido para o dessecador até atingir a temperatura ambiente. Por fim, o conjunto foi pesado com a resolução correspondente e sua massa foi registrada como $\mathrm{M} 2{ }^{[7]}$. Para o cálculo do teor de umidade (w) da amostra, utilizou-se a Equação 1, na qual M3 representa a massa do recipiente (placa de Petri), expressa em gramas.

$$
\mathrm{w}=\frac{(\mathrm{M} 1-\mathrm{M} 2) \cdot 100}{(\mathrm{M} 2-\mathrm{M} 3)}
$$

Foram realizadas três determinações de umidade da amostra e, em seguida, foi calculada a média das determinações efetuadas.

\subsection{Densidade}

As amostras foram pesadas em aproximadamente 10,00 g, em triplicata, utilizandose uma balança modelo PB3002-S, da Mettler Toledo, com resolução de 0,01 g. Depois, cada amostra foi colocada em uma proveta graduada de $50 \mathrm{~mL}$, com resolução de $1 \mathrm{~mL}$, contendo $20 \mathrm{~mL}$ de água.

Para a determinação do volume da amostra, subtraiu-se o volume inicial de água contida na proveta do volume final (água com amostra). A densidade, portanto, foi determinada pela razão entre a massa pesada da amostra posta na proveta com água e o respectivo volume de água deslocado na proveta.

\subsection{Análise Granulométrica por peneiramento}

A análise granulométrica foi realizada de forma adaptada, com base na norma ABNT NBR 7181:2016 [8]. Inicialmente, secou-se a amostra em estufa a $105^{\circ} \mathrm{C}$ e, posteriormente, essa foi deixada em repouso para atingir a temperatura ambiente. Em seguida, $2 \mathrm{~kg}$ desse material foram peneirados em uma série de peneiras acopladas a um agitador mecânico SOLOTEST.

Primeiro, realizou-se o "peneiramento grosso", caracterizado pela passagem do material pelas peneiras com abertura da malha de $50 \mathrm{~mm}, 37,5 \mathrm{~mm}, 25 \mathrm{~mm}, 19 \mathrm{~mm}$, $9,5 \mathrm{~mm}, 4,75 \mathrm{~mm}$ e $2 \mathrm{~mm}$ com auxílio do agitador mecânico por 20 minutos em 15 $\mathrm{Hz}$ de frequência e as massas retidas acumuladas em cada peneira foram anotadas. Em seguida, foi realizado o "peneiramento fino" do material que restou no fundo do "peneiramento grosso". Esse foi passado pelas peneiras com abertura de malha de $1,18 \mathrm{~mm}, 0,6 \mathrm{~mm}, 0,425 \mathrm{~mm}, 0,25 \mathrm{~mm}, 0,15 \mathrm{~mm}$ e $0,075 \mathrm{~mm}$ com o auxílio do agitador mecânico por 30 minutos em $15 \mathrm{~Hz}$ de frequência. As massas retidas acumuladas em cada peneira também foram anotadas com resolução de $0,1 \mathrm{~g}$.

O percentual mássico $(\mathrm{Qg})$ do material retido em cada peneira foi calculado utilizando-se a Equação 2.

$$
Q_{g}=\frac{\left(M_{s}-M_{r}\right) \times 100}{M_{s}}
$$


$\mathrm{Na}$ Equação 2, $\mathrm{M}_{\mathrm{s}}$ representa a massa total da amostra seca e $\mathrm{Mr}_{\mathrm{r}}$ representa a massa do material retido acumulado em cada peneira.

\subsection{Análise granulométrica por difração a laser}

A determinação da distribuição de tamanho de partículas foi feita a partir da análise das suas propriedades de dispersão da luz, empregando-se o analisador de partícula modelo Mastersizer 2000, da Malvern Instruments, de acordo com procedimento interno do LaPAQui/UFES, onde os testes foram realizados. A introdução das amostras foi realizada com o acessório Hydro 2000S, da Malvern Instruments, o qual possui um sistema de agitação associada a um pequeno sistema de ultrassom, que viabilizou a inserção da amostra e a limpeza do equipamento.

Com o conhecimento prévio da composição do material devido às análises descritas nos itens 2.2 e 2.8, tomou-se como objetivo determinar a granulometria da amostra com a seguinte composição: óxidos de ferro, óxido de silício, óxido de alumínio, óxido de zinco, óxido de magnésio e traços de dióxido de titânio, fósforo, enxofre, óxido de sódio e óxido de potássio.

\subsection{Difração de Raios-X (DRX)}

Utilizou-se o equipamento DRX da marca BRUKER, modelo D8 ADVANCE, com $2 \theta$ variando de $10^{\circ}$ até $100^{\circ}$, tensão em $30 \mathrm{kV}$, corrente em $10 \mathrm{~mA}$, velocidade de rotação de $10^{\circ} / \mathrm{min}$, passo de $0,02^{\circ}$, com tempo de exposição de 1 segundo e com radiação de cobre Cu-Ka, localizado no Laboratório de Redução do Instituto Federal do Espírito Santo (IFES), campus de Vitória.

A mesma pastilha completa $(\mathrm{d}<3 \mathrm{~mm})$ que foi utilizada nos testes realizados por FRX foi usada na análise por DRX. Com o auxílio do software DIFFRAC.SUITE EVA, interpretou-se os respectivos difratogramas de raios- $X$ obtidos.

\section{RESULTADOS E DISCUSSÃO}

\subsection{Análise Morfológica e Química}

\subsubsection{MEV/EDS}

Na Figura 3, são apresentadas as imagens de quatro pontos diferentes da amostra de "Terra de Sucata". Conforme pode ser visto nessa figura, o material apresenta um aspecto pouco uniforme, apresentando partículas de diferentes granulometrias. 

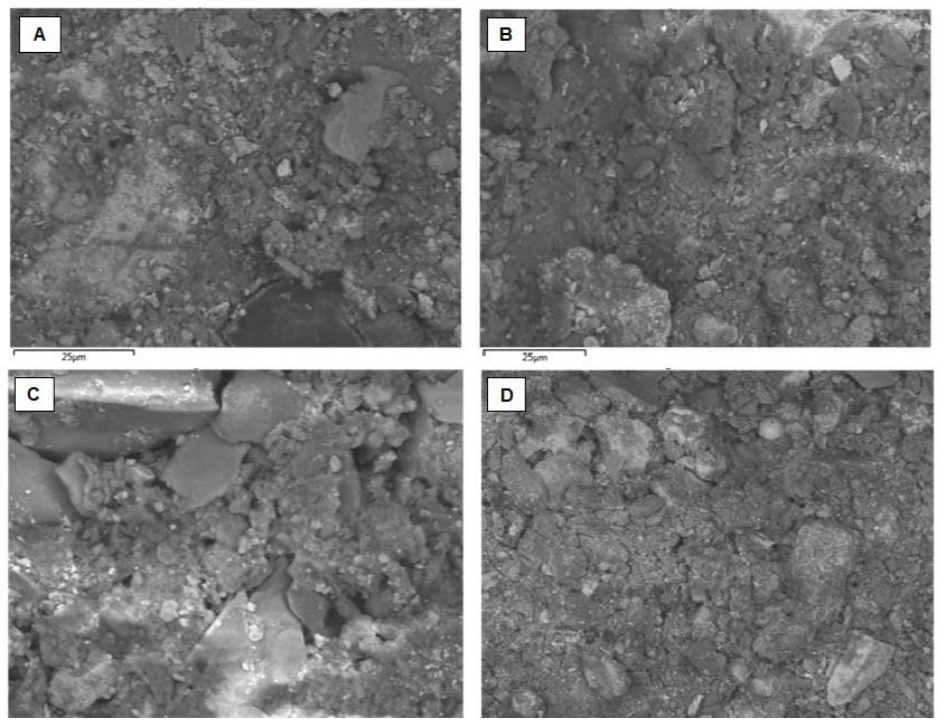

Figura 3. Detalhes das regiões $A, B, C$ e D da amostra.

Foram obtidos espectros de EDS em pontos específicos das regiões da amostra, as quais foram apresentadas na Figura 3. Nesses pontos, os elementos encontrados foram basicamente os mesmos nas diferentes regiões, porém, apresentaram diferenças nas concentrações. De forma geral, os elementos e suas respectivas faixas de concentração encontrados são listados na Tabela 1.

Tabela 1. Análise elementar da "Terra de Sucata" realizada pelo EDS.

\begin{tabular}{lccccccc}
\hline Elemento & $\mathbf{O}$ & $\mathbf{F e}$ & $\mathbf{A l}$ & $\mathbf{S i}$ & $\mathbf{C a}$ & $\mathbf{Z n}$ & $\mathbf{M g}$ \\
\hline Faixa de concentração (\%) & $45-60$ & $10-30$ & $5-10$ & $8-15$ & $5-6$ & $2-3$ & $1-3$ \\
\hline
\end{tabular}

O potássio e o titânio foram encontrados em pontos específicos, indicando que estão presentes na amostra apenas traços desses elementos. Para a confirmação desses resultados, utilizaram-se outros métodos de análise elementar, como a Fluorescência de Raios-X, por gerar resultados mais confiáveis.

\subsubsection{Fluorescência de Raios-X}

A Tabela 2 apresenta o resultado obtido a partir da técnica de FRX.

Tabela 2. Resultado da análise química por Fluorescência de Raios-X.

\begin{tabular}{|c|c|c|c|c|c|c|c|c|c|c|c|c|}
\hline Substância & $\mathbf{F e}$ & $\mathrm{SiO}_{2}$ & $\mathbf{A l}_{2} \mathrm{O}_{3}$ & $\mathbf{C a O}$ & $\mathbf{Z n O}$ & $\mathbf{M g O}$ & $\mathbf{M n}$ & $\mathbf{P}$ & $\mathbf{S}$ & $\mathrm{TiO}_{2}$ & $\mathrm{~K}_{2} \mathrm{O}$ & $\mathbf{N a}_{2} \mathrm{O}$ \\
\hline $\begin{array}{c}\mathrm{Teor} \\
\% \mathbf{m} / \mathbf{m} \\
(\mathbf{d}<\mathbf{3} \mathbf{m m})\end{array}$ & 49,4 & 18,1 & 6,6 & 8,2 & 1,0 & 3,6 & 0,7 & 0,1 & 0,1 & 0,6 & 0,2 & 0,6 \\
$\begin{array}{c}\mathrm{Teor} \\
\% \mathbf{m} / \mathbf{m} \\
(\mathbf{d}<\mathbf{8 4 0} \boldsymbol{\mu m})\end{array}$ & 48,4 & 20,7 & 7,9 & 7,2 & 1,8 & 3,5 & 0,6 & 0,1 & 0,1 & 0,6 & 0,3 & 0,6 \\
\hline
\end{tabular}

Vários resultados foram obtidos a partir das análises com diferentes curvas padrão. Dessa forma, selecionou-se o resultado gerado a partir do padrão para Sínter, visto que nenhum limite do padrão foi excedido. Conforme pode ser visto na Tabela 2, a amostra apresentou uma composição elementar bastante diversificada, o que indica a grande heterogeneidade da mesma. Tal característica também foi observada em outros trabalhos realizados com coprodutos do beneficiamento de sucata ${ }^{[9,10]}$, nos 
quais o fato de a sucata utilizada ter diferentes fontes foi o principal fator atribuído à heterogeneidade elementar observada em tais materiais.

\subsubsection{Teor de carbono}

O valor obtido para o teor de carbono da amostra $\mathrm{d}<840 \mu \mathrm{m}$ foi de $3,69 \%$ e o da amostra $\mathrm{d}<3 \mathrm{~mm}$ foi de 3,00\%. Como esses valores são baixos, pode-se afirmar que essas amostras apresentam um baixo teor de matéria orgânica e/ou um baixo teor de carbonatos.

\subsection{Difração de Raios-X}

Na Figura 4, é apresentado o difratograma de raios-X referente à "Terra de sucata".

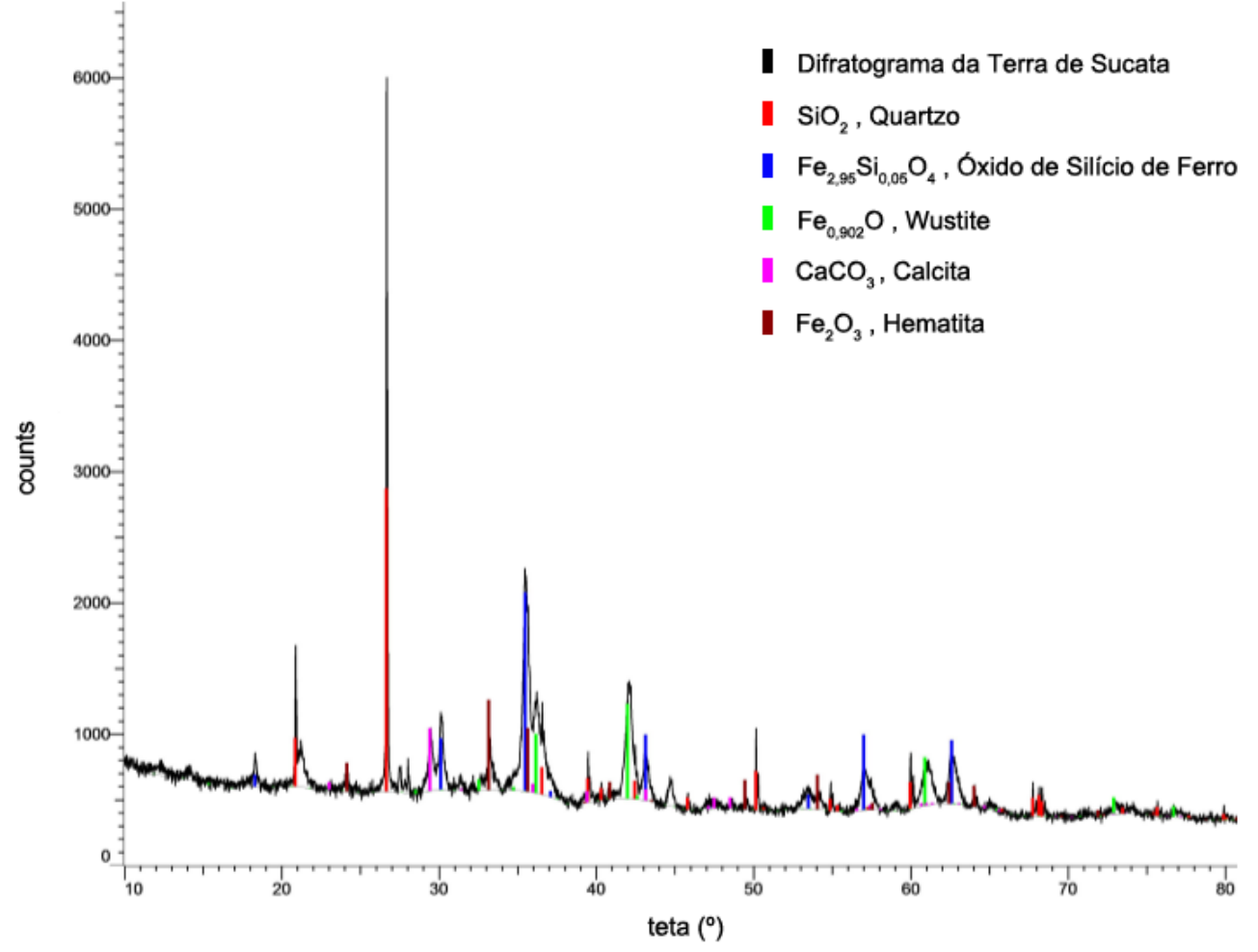

Figura 4. Difratograma da análise por DRX da "Terra de Sucata" com identificação dos picos.

De acordo com a Figura 4, a partir da superposição dos picos do difratograma geral com os dos componentes do banco de dados do software, foi possível identificar a presença dos seguintes compostos e suas fases na amostra: $\mathrm{SiO}_{2}$ (quartzo); $\mathrm{Fe}_{2} \mathrm{O}_{3}$ (hematita); $\mathrm{CaCO}_{3}$ (calcita); $\mathrm{FeO}$ (wustita) e óxido de silício e ferro.

Observa-se que apesar da FRX ter detectado a presença de vários elementos na amostra, poucos deles compõem as fases cristalinas identificadas com o auxílio da DRX. Isso pode ter ocorrido pelo fato da amostra ser muito heterogênea, gerando ruídos que dificultaram a identificação de muitos picos. Além disso, o pico de Quartzo, localizado no difratograma a $2 \theta=26^{\circ}$, por ser muito mais alto do que os demais, pode ter interferido na identificação dos picos menores. Dessa forma, sugere-se como trabalho futuro que seja feita uma separação do quartzo presente na amostra para, em seguida, realizar uma nova análise por DRX, de modo que talvez seja possível identificar fases cristalinas referentes aos elementos detectados pelas técnicas de EDS e FRX. 


\subsection{Potencial Hidrogeniônico, teor de umidade e densidade}

A partir dos ensaios de determinação de $\mathrm{pH}$, do teor de umidade e de densidade, observou-se que a "Terra de Sucata" apresenta pH próximo a neutralidade $(6,43 \pm$ $0,15)$, um baixo teor de umidade $(4,53 \% \pm 0,92 \%)$ e densidade igual a $2,25 \mathrm{~g} / \mathrm{cm}^{3} \pm$ $0,25 \mathrm{~g} / \mathrm{cm}^{3}$.

Os valores encontrados para os três parâmetros analisados se diferem dos obtidos por estudos sobre coprodutos do beneficiamento da sucata realizado em outras usinas siderúrgicas do país. Isso pode ser explicado pelo fato de essas indústrias utilizarem equipamento denominado Shredder para fazer a separação do material ferroso dos demais constituintes da sucata, o que não faz parte do beneficiamento da sucata realizado na planta industrial analisada no presente estudo ${ }^{[9,10]}$. Além disso, fatores como a origem da sucata e a forma de armazenamento podem influenciar os parâmetros físico-químicos em questão, visto que as plantas industriais comparadas estão localizadas em estados diferentes e possuem diferentes métodos de armazenamento em relação ao tempo em que o material fica na planta.

\subsection{Análise Granulométrica}

\subsubsection{Análise Granulométrica por Peneiramento}

As massas do material que ficaram retidas nas peneiras durante 0 ensaio granulométrico estão descritas na Tabela 3.

Tabela 3: Resultado do ensaio granulométrico feito com amostra de "Terra de Sucata".

\begin{tabular}{ccccc}
\hline $\begin{array}{c}\text { Abertura da } \\
\text { malha (mm) }\end{array}$ & $\begin{array}{c}\text { Massa } \\
\text { retida (g) }\end{array}$ & $\begin{array}{c}\text { Retido } \\
\text { acumulado (g) }\end{array}$ & $\begin{array}{c}\text { Material } \\
\text { Retido (\%) }\end{array}$ & $\begin{array}{c}\text { Material } \\
\text { passante (\%) }\end{array}$ \\
\hline 50,0 & 0,0 & 0,0 & 0,0 & 100,0 \\
37,5 & 0,0 & 0,0 & 0,0 & 100,0 \\
25,0 & 16,0 & 16,0 & 0,8 & 99,2 \\
19,0 & 63,8 & 79,8 & 3,2 & 96,0 \\
9,5 & 204,0 & 283,8 & 10,4 & 85,8 \\
4,8 & 350,2 & 634,0 & 17,8 & 68,3 \\
2,0 & 366,4 & 1000,4 & 18,6 & 50,0 \\
1,2 & 183,5 & 1183,9 & 9,3 & 40,8 \\
0,6 & 255,7 & 1439,6 & 13,0 & 28,1 \\
0,4 & 141,5 & 1581,1 & 7,2 & 21,0 \\
0,3 & 144,4 & 1725,5 & 7,3 & 13,8 \\
0,2 & 91,9 & 1817,4 & 4,7 & 9,2 \\
0,1 & 79,5 & 1896,9 & 4,0 & 5,2 \\
0,0 & 70,3 & 1967,2 & 3,6 & 1,7 \\
\hline
\end{tabular}

Observou-se uma massa retida acumulada no fundo de $1967,2 \mathrm{~g}$. Isso pode ser explicado por perdas de material fino durante a passagem de material da peneira para o recipiente de pesagem durante o ensaio. Além disso, a maior concentração de material está na faixa granulométrica de 2 a $4,75 \mathrm{~mm}$, somando a retenção de $36,4 \%$. No entanto, observa-se que há grande retenção de partículas em outras faixas granulométricas como 13,0\% para abertura de 0,6 mm, 10,4\% para abertura 
de 9,4 mm e 9,3 para abertura de 1,18 mm, o que indica que a "Terra de Sucata" é um material muito heterogêneo.

\subsubsection{Análise granulométrica por difração a laser}

$\mathrm{Na}$ Tabela 4, é apresentado o resultado da análise granulométrica por difração a laser que foi realizada com o material fino que passou por todas as peneiras empregadas na análise granulométrica por peneiramento.

Tabela 4: Diâmetro máximo de partículas presentes em diferentes percentuais da amostra $\left(D_{0,1}, D_{0,5}\right.$ e $D_{0,9}$, valores que cortam a distribuição granulométrica, respectivamente, em 10,50 e $90 \%$ do volume total).

\begin{tabular}{ccccc}
\hline Composição & *índice de Refração & $\mathbf{D}_{0,1}$ & $\mathbf{D}_{0,5}$ & $\mathbf{D}_{0,9}$ \\
\hline Óxido de Ferro & 2,98 & $27,264 \mu \mathrm{m}$ & $548,684 \mu \mathrm{m}$ & $1379,815 \mu \mathrm{m}$ \\
Óxido de Silício & 3,5 & $13,610 \mu \mathrm{m}$ & $364,761 \mu \mathrm{m}$ & $1175,351 \mu \mathrm{m}$ \\
Óxido de Cálcio & 1,83 & $5,919 \mu \mathrm{m}$ & $72,047 \mu \mathrm{m}$ & $662,685 \mu \mathrm{m}$ \\
Óxido de Alumínio & 1,763 & $10,553 \mu \mathrm{m}$ & $280,549 \mu \mathrm{m}$ & $1060,972 \mu \mathrm{m}$ \\
Óxido de Zinco & 2,02 & $8,414 \mu \mathrm{m}$ & $281,252 \mu \mathrm{m}$ & $1148,828 \mu \mathrm{m}$ \\
Óxido de Magnésio & 1,72 & $12,599 \mu \mathrm{m}$ & $444,793 \mu \mathrm{m}$ & $1297,413 \mu \mathrm{m}$ \\
Óxido de Titânio & 2,55 & $6,886 \mu \mathrm{m}$ & $221,272 \mu \mathrm{m}$ & $1022,424 \mu \mathrm{m}$ \\
\hline
\end{tabular}

*Índice de refração para os compostos químicos: foram utilizados os índices de refração disponíveis no equipamento Mastersizer 2000.

Foi possível determinar o diâmetro de partículas na faixa de 0,02 a $2000 \mu \mathrm{m}$ pela incidência da radiação laser em uma célula contendo a amostra dispersa em água. Observou-se que $90 \%$ dos principais constituintes da amostra possuem granulometria até aproximadamente $1,4 \mathrm{~mm}$. Além disso, $10 \%$ do material possui granulometria até, aproximadamente, $27 \mu \mathrm{m}$, o que indica a presença de silte e argila na amostra.

A partir da discrepância observada entre as granulometrias apresentadas na Tabela 4, entende-se que o material apresenta uma granulometria muito heterogênea, reforçando, assim, as observações feitas a partir dos resultados apresentados no item 3.4.1.

\section{CONCLUSÃo}

No presente trabalho, foi possível obter informações relevantes sobre as características físicas, químicas e físico-químicas da "Terra de Sucata". A partir dos testes realizados, observou-se que se trata de um material muito heterogêneo no que se refere à sua morfologia, composição química e granulometria. Esse material apresentou $\mathrm{pH}$ próximo à neutralidade, o que pode favorecer futuras aplicações. Além disso, foi constatado um alto teor de ferro nas análises elementares, indicando que há possibilidade do material ser reaproveitado na indústria siderúrgica caso passe por etapas de beneficiamento.

Acredita-se que o alto teor de sílica possa ter interferido na identificação de outras fases no resultado da análise de Difração de Raios-X. Portanto, recomenda-se realizar a separação da sílica da amostra a fim de identificar a presença outras fases. 
Estudos aprofundados devem ser realizados para que seja possível encontrar aplicações específicas para o material em questão.

\section{Agradecimentos}

À Universidade Federal do Espírito Santo e à empresa ArcelorMittal (unidades de Cariacica/ES e Tubarão/ES), juntamente com a equipe do Global Research and Development e do Laboratório de Aciaria e Coqueria pelo preparo e análise das amostras, assim como pelo suporte técnico prestado. Ao Laboratório de Preparo de Amostras e Análises Químicas (UFES, Campus de São Mateus) pelas análises de granulometria a laser e ao Laboratório de Redução - PROPEMM (IFES, Campus de Vitória) pelas análises de DRX.

\section{REFERÊNCIAS}

1 ADISSI, Paulo José; PINHEIRO, Francisco Alves; CARDOSO, Rosângela da Silva. Gestão ambiental de unidades produtivas. Elsevier Brasil; 2013.

2 INSTITUTO AÇO BRASIL (IAB). Relatório de sustentabilidade 2016. Disponível em: <http://www.acobrasil.org.br/sustentabilidade/>. Acesso em: 19 out. 2016.

3 MOURÃO, Marcelo Breda. Introdução a Siderurgia: Histórico dos Processos de Obtenção de Ferro e Aço. São Paulo: Associação Brasileira de Metalurgia e Materiais. 2007. 1-20p.

4 ASSOCIAÇÃO BRASILEIRA DE NORMAS TÉCNICAS, 2004. Amostragem de Resíduos Sólidos - NBR 10007/2004.

5 LUZ, Adão Benvindo da; SAMPAIO, João Alves; FRANÇA, Silvia Cristina Alves. Tratamento de minérios.5a edição. - Rio de Janeiro: CETEM/MCT. 2010. GOOGLE MAPS, 2016. Disponível em: <https://www.google.com.br/maps/place/ArcelorMittal+Cariacica/@-20.3504412,40.3611895,413m/data=!3m1!1e3!4m5!3m4!1s0xb83c284264d38f:0x7ec3f379898c8e0 $0 ! 8 m 2 ! 3 d-20.3440803 ! 4 d-40.3612436>$. Acesso em: 28 out. 2016.

7 ASSOCIAÇÃO BRASILEIRA DE NORMAS TÉCNICAS (ABNT). NBR 6457 - versão corrigida: Amostras de solo - Preparação para ensaios de compactação e ensaios de caracterização. Rio de Janeiro, 2016.

8 ASSOCIAÇÃO BRASILEIRA DE NORMAS TÉCNICAS (ABNT). NBR 7181: Solo Análise Granulométrica. Rio de Janeiro, 2016.

9 BATISTA, Daniella Cristina. Classificação e caracterização dos resíduos do beneficiamento da sucata de ferro e aço utilizada no processo siderúrgico para identificação de viabilidade de aplicações. 2012. 80f. Dissertação (Mestrado em Engenharia de Minas, Metalúrgica e de Materiais) - Escola de Engenharia, Universidade Federal do Rio Grande do Sul, Porto Alegre, 2012.

10 RECKZIEGEL, Viviana Nedel. Caracterização para aproveitamento do resíduo de um triturador de sucata em uma usina siderúrgica. 2012. 80f. Dissertação (Mestrado em Engenharia de Minas, Metalúrgica e de Materiais) - Escola de Engenharia, Universidade Federal do Rio Grande do Sul, Porto Alegre, 2012. 